\section{Tropical Journal of Pathology and Microbiology}

\title{
Study of coagulation profile in malaria
}

\section{K Patel V. ${ }^{1 *}$, Kalpesh Shah N. ${ }^{2}$, Deepak Goyal A. ${ }^{3}$, Kalpesh Shah C. ${ }^{4}$, Jagdish Patel S. ${ }^{5}$ \\ DOI: https://doi.org/10.17511/jopm.2020.i08.01}

1* Vibha K Patel, MD Pathology, Smt. NHL Municipal Medical College, V.S. General Hospital, Ahmedabad, Gujarat, India.

2 Nirali Kalpesh Shah, Assistant Professor, Department of Pathology, Gujarat Medical Education and Research Society, Ahmedabad, Gujarat, India.

3 Anjali Deepak Goyal, Associate Professor, Smt. NHL Municipal Medical College, V.S. General Hospital, Ahmedabad, Gujarat, India.

${ }^{4}$ Cherry Kalpesh Shah, Professor and Head of the Department, Smt. NHL Municipal Medical College, V.S. General Hospital, Ahmedabad, Gujarat, India.

5 Simul Jagdish Patel, MD Pathology, Smt. NHL Municipal Medical College, V.S. General Hospital, Ahmedabad, Gujarat, India.

Background: Malaria is a major health problem in many parts of India. Several factors have been attributed to increased morbidity and mortality in malaria with altered hematological and coagulation parameters. This study was conducted to compare the coagulation parameters of malaria cases with those of the healthy carriers. Aims and objectives: To evaluate coagulation abnormalities in patients of malaria and to study the difference in coagulation parameters between malaria patients and healthy controls and to determine the level of significance of the difference. Materials and methodology: This prospective comparative study of 300 patients with laboratory diagnosed malaria patients (cases) and 300 healthy individuals (controls) was carried out in the Department of Pathology in a tertiary care, V. S. General Hospital, Ahmedabad. Result: Comparison of platelet count, PT, and aPTT between case groups and control groups was statistically significant $(p<0.001)$. Conclusion: There is a significant difference between the platelet count, PT, and aPTT values of the two groups. This indicates that in patients with malaria, there is an activation of intrinsic and extrinsic pathways of coagulation.

Keywords: Malaria, Coagulation profile, Platelet count, PT, aPTT, D-dimer

\section{Corresponding Author}

Vibha K Patel, MD Pathology, Smt. NHL Municipal Medical College, V.S. General Hospital, Ahmedabad, Gujarat, India.

Email: drvibhapatel29@gmail.com

\section{How to Cite this Article}

Patel VK, Shah NK, Goyal AD, Shah CK, Patel SJ. Study of coagulation profile in malaria. Trop J Pathol Microbiol. 2020;6(8):459-465.

Available From

https://pathology.medresearch.in/index.php/jopm/ar ticle/view/491
To Browse

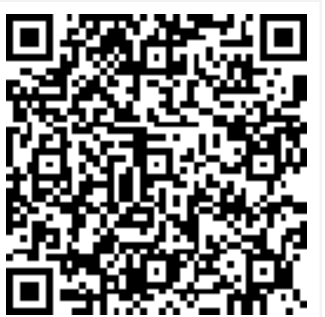

Manuscript Received 2020-10-29

Conflict of Interest No 2020-11-09

Funding
Review Round 2 2020-11-20

Ethical Approval Yes
Review Round 3

Plagiarism X-checker $8 \%$
Accepted 2020-12-15

(c) 2020 by Vibha K Patel, Nirali Kalpesh Shah, Anjali Deepak Goyal, Cherry Kalpesh Shah, Simul Jagdish Patel and Published by Siddharth Health Research and Social Welfare Society. This is an Open Access article licensed under a Creative Commons Attribution 4.0 International License https://creativecommons.org/licenses/by/4.0/ unported [CC BY 4.0]. 


\section{Introduction}

Malaria is a mosquito-borne infectious disease caused by parasitic protozoans of the genus Plasmodium [1]. The parasites causing malaria are members of the Haemosporidiae. These parasites of the genus Plasmodium are transmitted to human beings by a pre-infected female anopheles mosquito bite. Four species are generally recognized in man:

(1) P. falciparum (the malignant tertian malaria parasite)

(2) P. vivax (the benign tertian malaria parasite)

(3) P. ovale (the benign tertian malaria parasite)

(4) P. malariae (the quartan malaria parasite). P.falciparum produces the most serious form of the disease and is responsible for most malaria-related deaths [2].

A variety of hematological alterations like progressively increasing anemia, thrombocytopenia, leucopenia occur in malaria. The derangement in the coagulation profile in malaria is a highly sensitive measure to access the severity and activity of the disease process. There is an accelerated coagulation cascade activity with accelerated fibrinogen turnover, consumption of antithrombin-III (AT-III), and increased concentration of fibrinogen degradation products.

Erythrocytes (RBCs) containing parasites are procoagulant. Released cytokines also act as procoagulants. Prothrombin time (PT) and activated partial PT (aPTT) is prolonged. Severe hemorrhage is reported in $5 \%$ of severe malaria [2]. The patient may develop bleeding gums, epistaxis, petechiae, subconjunctival hemorrhages, melena, and hematemesis [3].

\section{Aims and Objectives}

01. To evaluate coagulation abnormalities likeprothrombin time (PT), activated partial thromboplastin time (aPTT), and fibrinogen degradation product ( $\mathrm{D}$-dimer) in patients of malaria.

02. To study the difference in coagulation parameters between malaria patients and healthy controls and to determine the level of significance of the difference.

03. To understand the severity of coagulation defects and their related complications in patients with malaria.

\section{Materials and Methodology}

Type of study: Prospective study

Place and duration of study: This prospective comparative study was carried out in the Department of Pathology in tertiary care, V. S. General Hospital, Ahmedabad, and the duration of the study is 2 years.

Sample size: 300 patients with laboratory diagnosed malaria patients (cases) and 300 healthy individuals (controls)

Sampling methods: A comprehensive history including presenting complaints (Fever spikes, chills and rigor at regular intervals; classical malarial paroxysms: three stages- Cold stage, Hot stage and the Sweating stage and manifestations of severe $P$. Falciparum malaria), history, family history, drug history was taken by asking questions through a structured questionnaire. Patients of both sexes ranging from 3 years to 70 years were selected as per the below criteria:

\section{Inclusion criteria:}

- Cases: Indoor and outdoor malaria positive cases satisfying the following criteria were included in the study:

- Age $>3$ years of either sex

- Slide positive malaria cases (P.vivax or falciparum)

- Previously untreated for a present episode of

- Controls: Healthy individuals who did not have any features suggesting abnormalities related to hematological, biochemical, or coagulation parameters and not taking any anticoagulant therapy.

\section{Exclusion criteria:}

Patients with clinical history and or finding suggestive of

- Chronic liver disease

- Hemostatic abnormalities (aplastic anemia, leukemia, lymphoma, and vasculitis)

- Drugs used (sulphonamides, penicillin, cephalosporin, thiazide, and cytotoxic drugs).

- Congenital clotting factor defects (hemophilia, afibrinogenaemia, factor $V$ and XI deficiencies

\section{Technical details:}

Collection of blood: 
01. For Hemoglobin, Total WBC count and Platelet count: $2 \mathrm{ml}$ of blood was collected in EDTA vacuttee

02. For PT, aPTT, and D-dimer: $2 \mathrm{ml}$ of venous blood was collected in $3.2 \%$ citrate

\section{Processing of sample for coagulation studies:}

Samples of the patients were immediately transported to the laboratory and were centrifuged at 3000-4000 revolutions for 15-30 minutes to obtain platelet-poor plasma ( $<10,000 /$ cumm). Platelet poor plasma was used in PT, aPTT, and Ddimer. Samples were tested within 6 hours of collection of blood samples.

\section{Investigations:}

01. Peripheral smear: The clinical diagnosis of malaria was confirmed by peripheral blood smear examination which is the gold standard for the diagnosis of

For microscopic examination, peripheral blood thin and thick films were made on different slides (as per the method described in Practical HematologyDacie and Lewis) and stained with field's stain. Grading of parasitemia (by semi-quantitative scale) was done from thick film examination.

02. Hematological examination: Complete hemogram with CELLDYN Ruby (Abbott) and Abbott CELLDYN 3700. Hemoglobin with less than $12.5 \mathrm{mg} / \mathrm{dl}$ was taken altered. Leucopenia with total white blood cell count $<4000 /$ cumm was taken altered. Thrombocytopenia with platelet count $<1.5$ lakh/cumm were taken
03. Coagulation profile: Was assessed by measuring prothrombin time (PT), activated partial thromboplastin time (aPTT), fibrinogen degradation products ( $\mathrm{D}$-dimer) by ACL Elite Pro Coagulation Analyser (Instrumentation Laboratory).

\section{Statistical analysis:}

- Comparison of platelet count, PT, and aPTT between case and control were done by using Mean \pm SD and students unpaired $\mathrm{t}$ -

- p-value $<0.05$ was taken to indicate a statistically significant

- All statistical analysis was done by using software Microsoft excel 2010 version and SPSS (statistical package for the social sciences) 21.0 version.

\section{Results}

Study shows that, out of 300 patients, 82 patients were affected by P. falciparum (27.3\%), and 218 patients $(72.7 \%)$ were affected by P. Vivax. Overall there were $7.67 \%$ pediatric patients in the study with P. falciparum patients being $10.9 \%$ of all P. falciparum cases and P. Vivax cases being $6.4 \%$ of all P. Vivax cases.

In both species, the majority of patients were adults. Out of 82 P. Falciparum cases, $26(31.7 \%)$ were females and $56(68.3 \%)$ were males. Out of 218 P. Vivax cases, $64(29.3 \%)$ were females and $154(70.7 \%)$ were males.

Table-1: Comparison of Mean between P. Falciparum and P. Vivax of baseline hemogram parameters.

\begin{tabular}{|c|c|c|c|c|c|}
\hline & & Number of cases & Mean Value & Minimum Value & Maximum Value \\
\hline \multirow[t]{3}{*}{ Hemoglobin } & P. falciparum & 82 & $9.4 \pm 2.8$ & 4.2 & 16 \\
\hline & P. vivax & 218 & $10.6 \pm 2.6$ & 3.3 & 17.1 \\
\hline & Total & 300 & $10.3 \pm 2.7$ & 3.3 & 17.1 \\
\hline \multirow[t]{3}{*}{ WBC Count } & P. falciparum & 82 & $7009.5 \pm 5107.3$ & 1620 & 32700 \\
\hline & P. vivax & 218 & $5875.9 \pm 2510.4$ & 1390 & 19700 \\
\hline & Total & 300 & $6185.8 \pm 3449.1$ & 1390 & 32700 \\
\hline \multirow[t]{3}{*}{ Platelet Count } & P. falciparum & 82 & $66258.3 \pm 45947.7$ & 6000 & 227000 \\
\hline & P. vivax & 218 & $98692.6 \pm 58810.6$ & 8000 & 382000 \\
\hline & Total & 300 & $89827.3 \pm 57373.6$ & 6000 & 382000 \\
\hline \multirow[t]{3}{*}{ RBC Count (lacs) } & P. falciparum & 82 & $3.7 \pm 1.1$ & 1.5 & 5.9 \\
\hline & P. vivax & 218 & $4.3 \pm 0.9$ & 1.5 & 6.5 \\
\hline & Total & 300 & $4.1 \pm 1.0$ & 1.5 & 6.5 \\
\hline
\end{tabular}


Anemia was observed in $55 \%$ of all patients, Leukopenia was observed in $22 \%$ of patients, and thrombocytopenia was seen in $85.7 \%$ of patients who presented with malaria.

Table-2: Changes in coagulation profile in malaria.

\begin{tabular}{|l|l|l|l|}
\hline \multirow{2}{*}{ Parameter } & \multicolumn{2}{c|}{ Species } & \multirow{2}{*}{ Total } \\
\cline { 2 - 3 } & P. Falciparum & P. Vivax & \\
\hline PT>15.3 Seconds & $34(41.4 \%)$ & $95(43.6 \%)$ & $129(43 \%)$ \\
\hline APTT> 38 Seconds & $26(31.7 \%)$ & $73(33.5 \%)$ & $99(33 \%)$ \\
\hline D-Dimer(>255ng/DI) & $4(4.9 \%)$ & $1(0.4 \%)$ & $5(1.7 \%)$ \\
\hline Total Enrolled Patients & $82(100 \%)$ & $218(100 \%)$ & $300(100 \%)$ \\
\hline
\end{tabular}

PT was prolonged in $41.4 \%$ and $43.6 \%$ of $\mathrm{P}$. falciparum and P. vivax patients respectively.

Similarly, APTT was prolonged in $31.7 \%$ and $33.5 \%$ of P. falciparum and P. vivax patients respectively.

D-Dimer was elevated in only $1.7 \%$ of all malaria patients.

Table-3: Comparison of coagulation profile between 300 patients with malaria and 300 healthy individuals (controls) were as follows.

\begin{tabular}{|l|l|l|l|}
\hline Parameters & \multicolumn{1}{|c|}{$\begin{array}{c}\text { Study } \\
\text { Group }(\mathbf{n}=\mathbf{3 0 0})\end{array}$} & \multicolumn{1}{|c|}{$\begin{array}{c}\text { Control } \\
\text { Group }(\mathbf{n}=\mathbf{3 0 0})\end{array}$} & $\begin{array}{c}\text { p-value (unpaired } \\
\text { t-test) }\end{array}$ \\
\hline PT & $15.74 \pm 2.71$ & $13.89 \pm 2.02$ & $<0.001$ \\
\hline Aptt & $37.429 \pm 5.51$ & $33.148 \pm 1.97$ & $<0.001$ \\
\hline $\begin{array}{l}\text { Platelet } \\
\text { Count }\end{array}$ & $89827.267 \pm 5737$ & $292427.93 \pm 50027$. & $<0.001$ \\
\hline
\end{tabular}

Data was presented as Mean $\pm S D$, unpaired t-test was applied.

P-value of $<0.05$ was considered a statistically significant difference.

Thus, there was a statistically significant decrease in platelet count as well as an increase in PT and aPTT in patients with malaria as compared to controls.

Table-4: Comparison of coagulation profile between $P$. Falciparum and P. Vivax malaria were as follows.

\begin{tabular}{|c|c|c|c|}
\hline $\mid \begin{array}{c}\text { Parameter } \\
\mathrm{s}\end{array}$ & $\begin{array}{l}\text { P. falciparum } \\
(\mathrm{n}=\mathbf{8 2})\end{array}$ & $\begin{array}{l}\text { P. vivax } \\
(\mathrm{n}=218)\end{array}$ & $\begin{array}{c}\mathrm{p} \text { - value (unpaired } \mathrm{t}- \\
\text { test) }\end{array}$ \\
\hline PT & $15.56 \pm 2.85$ & $15.81 \pm 2.66$ & 0.5 \\
\hline aPTT & $37.37 \pm 5.49$ & $37.45 \pm 5.52$ & 0.9 \\
\hline $\begin{array}{l}\text { Platelet } \\
\text { Count }\end{array}$ & $\begin{array}{l}66258.29 \pm 45947.6 \\
7\end{array}$ & $\begin{array}{l}98692.66 \pm 58810 \\
.59\end{array}$ & $<0.001$ \\
\hline
\end{tabular}

Data was presented as Mean $\pm S D$, unpaired t-test was applied. P-value of $<0.05$ was considered a statistically significant difference.
Thus, there was no significant difference in values of PT and aPTT amongst P. falciparum and P. vivax patients, however, platelet count was significantly lower in P. falciparum patients as compared to $\mathrm{P}$. vivax patients.

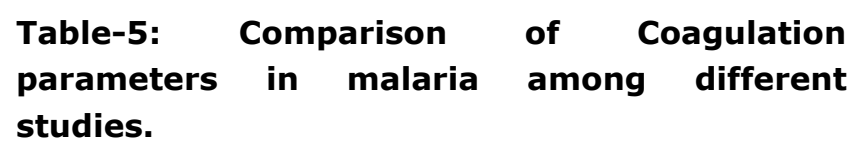

\begin{tabular}{|l|l|l|l|}
\hline \multirow{2}{*}{ Studies } & \multicolumn{3}{|c|}{ Percentage of cases with altered Coagulation Profile } \\
\cline { 2 - 4 } & Altered PT & Altered aPTT & Altered Platelet \\
\hline Present Study & $43 \%$ & $33 \%$ & $85.7 \%$ \\
\hline $\begin{array}{l}\text { Previous } \\
\text { studies }\end{array}$ & $38 \%$ & $56 \%$ & $96 \%$ \\
\hline $\begin{array}{l}\text { Previous } \\
\text { studies }\end{array}$ & $34 \%$ & $12 \%$ & $68 \%$ \\
\hline $\begin{array}{l}\text { Previous } \\
\text { studies }\end{array}$ & $47.5 \%$ & $35 \%$ & $85 \%$ \\
\hline $\begin{array}{l}\text { Previous } \\
\text { studies }\end{array}$ & $21 \%$ & $31 \%$ & $63 \%$ \\
\hline
\end{tabular}

PT and aPTT were prolonged in $43 \%$ and $33 \%$ of the malaria patients respectively The derangement in values is comparable with those of Prasad $R$ et al. and Kini et al who noted prolongation of PT in $47.5 \%$ and $38 \%$ of cases and deranged aPTT in $35 \%$ and $56 \%$ of cases, respectively.

\section{Discussion}

\section{Pathophysiologic mechanisms of coagulopathy in malaria}

\section{Mechanisms of Thrombocytopenia in Acute} Malaria

- Antibody-Mediated:

Antiphospholipid antibodies occur in patients with falciparum and vivax malaria and it has been suggested that they may be, at least partially, responsible for platelet activation and thrombocytopenia. Antiplatelet antibodies may activate platelet membranes, resulting in their removal by the hyperplastic reticuloendothelial (RE) system, particularly the spleen.

\section{- Erythrocyte ADP Release:}

It has been suggested that ADP, released by the hemolysis of erythrocytes activates platelets, which are then removed by the spleen.

- Platelet Phagocytosis:

Platelets are removed by activated macrophages in the spleen and liver. 


\section{- Oxidative Stress:}

Oxidative stress may, through lipid peroxidation, cause premature platelet death, leading to malariaassociated thrombocytopenia.

\section{- Platelet dysfunction:}

During acute, P. falciparum and P. vivax infection, hyper aggregation and enhanced platelet secretory activity are demonstrated. This in vitro study suggested that the interaction between normal platelets and falciparum-infected erythrocytes could induce hypersensitivity of platelets, possibly through the stimulation of ADP released from infected red cells. Antibody bound to platelets as well as the invasion of platelets by malarial parasites may be other response mechanisms.

The other aspect of platelet dysfunction during malarial infection observed in some patients is the defective aggregation of platelets in response to ADP, epinephrine, and collagen and not ristocetin. From electron microscopic study, circulating degranulated platelets were observed during malarial infection. The presentation of the circulating exhausted platelets as a result of persistent in vivo activation is most likely a responsible mechanism causing the platelet hypoactivity [4].

\section{Coagulation activation}

During severe complicated malarial infection, the activation of the coagulation system leading to in vivo thrombin generation has been demonstrated. The stimulation of the coagulation system is caused by various procoagulants present during malarial infection. The sources of the procoagulants are exposed phosphatidylserine on the cell surface of infected erythrocytes, the lysis of activated platelets together with their secretory products, and the tissue factor (TF) released from damaged vascular endothelial cells. (4)

Furthermore, certain substances that are released during a severe malarial infection -namely tumor necrosis factor a (TNF a) and histamine - are additional factors that promote fibrin formation. The intrinsic pathway of the coagulation has also been shown to be activated in severe malaria. In turn, this may cause activation of the complement system and release of bradykinin and $\mathrm{PMN}$-derived elastase that could contribute to the pathogenesis of severe malaria. Activation of the coagulation cascade also occurs in mild malaria.
The degree of activation is proportional to disease severity. Several sensitive indices of intravascular coagulation, including decreased plasma antithrombin(AT) activity and increased concentrations of thrombin antithrombin(TAT) complexes, are proportional to disease severity [5].

\section{Defects in inhibitors of coagulation}

Protein C, protein S, and AT levels were found to be low in P. falciparum, particularly in complicated cases, but were normal in P. vivax infection. The reduction in the levels of protein $C$, protein $S$, and AT is attributed to increased consumption due to microvascular thrombosis despite normal synthesis in the liver, as they correlated inversely with levels of TAT complexes [6].

\section{- /Impaired fibrinolysis}

Plasma levels of plasminogen activator inhibitor-1 (PAI-1) were very high in cases of P. falciparum infection as compared to normal controls and $P$. vivax infection. This could contribute to impaired fibrinolysis. The elevation of PAI- 1 also strongly correlated with a decrease in the coma scale in cerebral malaria patients and correlated inversely with a reduction in platelet count, protein $\mathrm{C}$, protein $S$, and AT levels. Both functional and antigenic tissue plasminogen activator (tPA) levels were low [6].

\section{- Cytokines}

Serum TNFa and interleukin-6 levels were elevated in the majority of patients with $\mathrm{P}$. falciparum infection before antimalarial treatment. TNFa was also found to reduce the secretion of tPA and increase the secretion of PAI-1 [7].

Table-6: Acute versus "compensated" disseminated intravascular coagulation (DIC): an important distinction.

\begin{tabular}{|c|c|c|}
\hline \multicolumn{3}{|c|}{ Profile of acute and compensated DIC } \\
\hline \multirow[b]{2}{*}{ Characteristic } & \multicolumn{2}{|l|}{ DIC } \\
\hline & Acute & Compensated \\
\hline Prothrombin time & $\uparrow$ & $\mathrm{N}$ or $\mathrm{S}$ \\
\hline Partial thromboplastin time & $\uparrow$ & $\mathrm{N}$ or $\mathrm{S}$ \\
\hline Platelet count & $\downarrow$ & $\downarrow$ or $\mathrm{N}$ \\
\hline Fibrinogen level & $\downarrow$ & $\downarrow$ or $N$ or $\uparrow$ \\
\hline D- dimer & $\uparrow$ & $\uparrow$ or $\mathrm{N}$ \\
\hline Fibrinogen degradation products & $\uparrow$ & $\mathrm{N}$ or $\uparrow$ \\
\hline Fibrin monomer & $\uparrow$ & $\mathrm{N}$ or $\uparrow$ \\
\hline Thrombin-antithrombin complex & $\uparrow$ & $\uparrow$ \\
\hline Plasmin-antiplasmin complex & $\uparrow$ & $\uparrow$ \\
\hline Bleeding and hemorrhage & + & - \\
\hline
\end{tabular}




\section{- Endothelial cell activation}

The mechanisms involved in vascular endothelial cell damage in severe complicated malaria are multifactorial. A significant rise in plasma levels of both von Willebrand factor (vWF) and its propeptide, indices of chronic and acute endothelial cell perturbation, respectively. The increased levels indicate endothelial damage by the parasitized erythrocytes [7].

In uncomplicated and severe malaria, a coagulation disorder is a common laboratory finding, but bleeding and hemorrhage are observed in very few cases of severe malaria. Therefore, an important distinction should be made between these two pathologic states, one where typical DIC is encountered(e.g., bleeding), and the other where a compensated state (e.g., laboratory changes only) is detectable. DIC is characterized by activation of the coagulation cascade, which leads to the formation of microthrombi in the microcirculation, sometimes localized to a specific organ, but it often presents with an uneven distribution. Two major mechanisms trigger DIC: the release of TF into the circulation or endothelial injury.

While acute DIC is the terminal phase of the coagulation disorder, it is often preceded by a period during which the coagulation cascade is already activated but the increased activation can be compensated by the natural inhibitor systems, a state referred to as compensated DIC. The control mechanisms may effectively prevent severe clinical manifestations such as bleeding and hemorrhage by neutralizing active enzymes and/or by increasing the synthesis of the consumed hemostatic components.

As the trigger for coagulation activation persists in DIC, inhibitors will be gradually exhausted, leading to more coagulation. In this process, many clotting factors-like, fibrinogen and platelets-are consumed, resulting in eventually incomplete impairment of the hemostasis system. This is why the term 'consumptive coagulopathy' is often used to denote this process. This results in bleeding tendency or decompensated DIC.

Also, activation of the coagulation cascade is accompanied by compensatory fibrinolysis where an increase in plasminogen-dependent plasmin activity is detected using markers such as D-dimers, as shown in the above table. It also depicts the laboratory profile of acute and 'compensated' DIC [8].

\section{Limitations}

- The signs and symptoms of malaria may overlap with those of other infections. Therefore, the assessment of patients for other possible infections is of paramount importance.

- Leucocyte changes in malaria are variable and may not correlate exactly with the level of parasitemia.

- Thrombocytopenia may not be evident in some malaria cases, so careful peripheral smear examination is mandatory for accurate reporting.

- Derangement in coagulation profile may not be evident with the very low level of parasitemia.

\section{Conclusion}

There is a significant difference between the platelet count, PT, and APTT values of the two groups. This indicates that inpatient with malaria there is an activation of intrinsic and extrinsic pathways of coagulation.

\section{What does the study add to the existing knowledge?}

The present study concluded that activation of the coagulation cascade is not confined to $P$ falciparum alone but is also seen in significant percentages of patients with $P$ vivax infection. Moreover, most of the cases of malaria remain in a state of compensated DIC wherein the activated factors are kept in check by the anticoagulant mechanisms.

\section{Author's contribution}

All the authors, Dr. Vibha Kantilal Patel, Dr. Nirali Kalpesh Shah, Dr. Anjali Deepak Goyal, Dr. Cherry Kalpesh Shah, Dr. Simul Jagdish Patel have contributed to the concept, literature search, data acquisition, data analysis, manuscript editing, and review.

\section{Reference}

01. Lee GR, Bithel TC, Foerster JA, Athens JW, Leukens JN. Wintrobe's Clinical hematology, 9th edition, London. Lea \& Febiges. 1993;1(2)1981201.

[Crossref] 
02. Park KS. Arthropod born infection. Park's textbook of Preventive \& Social Medicine, 19th edition, Jabalpur. $2007 ; 5 ; 209-220$.

[Crossref]

03. Mepherson RA, Pincus MR. Blood \&Tissue Protozoa, Henry's Clinical Diagnosis \& Management by Laboratory Methods. 21st ed, Elsevier. 2007;67;1127-1134.

[Crossref]

04. Mohanty D, Marwaha N, Ghosh K, Sharma S, Garewal G, Shah S, et al. Functional and ultrastructural changes in malarial infection. Trans R Soc Trop Med Hyg. 1988;82(3)369-375. doi: 10.1016/0035-9203(88)90122-8 [Crossref]

05. Pukrittayakamee $S$, White NJ, Clemens R, Chittamas S, Karges HE, Desakorn V, et al. Activation of the coagulation cascade in falciparum malaria. Trans R Soc Trop Med Hyg. $1989 ; 83(6) 762-766$.

doi: 10.1016/0035-9203(89)90321-0 [Crossref]
06. Mohanty D, Ghosh K, Nandwani SK, Shetty S, Phillips C, Rizvi S, et al. Fibrinolysis, inhibitors of blood coagulation, and monocyte derived coagulant activity in acute malaria. Am J Hematol. 1997;54(1)23-29.

doi: $10.1002 /($ sici)1096-8652(199701)54:1<23: :aidajh4>3.0.co;2-6 [Crossref]

07. Hemmer CJ, Kern P, Holst FGE, Radtke KP, Egbring $R$, Bierhaus $A$, et al. Activation of the host response in human Plasmodium falciparum malaria- relation of parasitemia to tumor necrosis factor/cachectin, thrombinantithrombin III, and protein C levels. Am J Med. $1991 ; 91(1) 37-44$.

doi: 10.1016/0002-9343(91)90071-5 [Crossref]

08. Francischetti IM, Seydel KB, Monteiro RQ. Monteiro- Blood Coagulation, Inflammation and Malaria. Microcirc. 2008;15(2)81-107. doi: $10.1080 / 10739680701451516$

[Crossref] 